\title{
Fat-Free Mass and Fasting Glucose Values in Patients with and without Statin Therapy Assigned to Age Groups between $<60$ and $>75$ Years
}

\author{
Alexander Dzien $^{\mathrm{a}}$ Hannes Winner ${ }^{\mathrm{b}}$ Engelbert Theurl ${ }^{\mathrm{c}}$ Christine Dzien- \\ Bischinger $^{a}$ Monika Lechleitner ${ }^{d}$ \\ ${ }^{a}$ Medical Center Hentschelhof, Innsbruck, ${ }^{b}$ Department of Economics and Social Sciences, University \\ of Salzburg, Salzburg, ' Department of Public Economics, University of Innsbruck, Innsbruck, \\ ${ }^{d}$ Department of Internal Medicine, Hospital Hochzirl, Zirl, Austria
}

\section{Key Words}

Fat-free mass · Aging · Statin

\begin{abstract}
Objective: The aging-associated changes in body composition result in an increased cardiometabolic risk. A tremendous reduction of cardiovascular morbidity and mortality can be obtained by statin therapy. Statins are well tolerated, with myopathy as the most serious negative side effect. Some recently published studies indicate that the incidence of type 2 diabetes might be increased during intensified statin therapy. The aim of our study was to investigate whether statin therapy has an influence on the aging-associated changes in fat-free mass (FFM). Methods: A total of 3,280 persons attending a medical outdoor center between January 2005 and July 2011 were assigned to 3 age groups from $<60$ to $>75$ years. Clinical data, body mass index (BMI), and body composition were evaluated in the different age groups in patients with and without statin therapy. To analyze the impact of statin use on FFM, we regressed a patient's FFM on an interaction term between statin use and age and other control variables. Results: Aging was associated with a decrease in BMI and FFM, while fat mass continuously increased up to the age of $>75$ years. This was paralleled by a continuous increase in fasting glucose levels in patients with and without statin therapy. The loss of FFM between the age group $<60$ years and $>75$ years was more pronounced in statin-treated patients $(10.88 \%)$ than in non-statin users (8.47\%). Creatine phosphokinase values revealed a decrease of $7.77 \mathrm{U} / \mathrm{l}$ between the age groups $<60$ and $>75$ years in non-statin users and of $14.75 \mathrm{U} / \mathrm{l}$ in statin users. Statistical analysis indicated that the effect of statin therapy on FFM is more pronounced in younger than in older patients. Conclusions: Patients under statin therapy seem to be more vulnerable to the aging-associated lowering of FFM. Diagnostic procedures and interventions to prevent a loss of muscle mass might be of particular advantage in elderly patients under statin therapy.


Dzien et al.: Fat-Free Mass and Fasting Glucose Values in Patients with and without Statin Therapy Assigned to Age Groups between $<60$ and $>75$ Years

\section{Background}

Aging is related to a decrease in muscle mass and an increase in fat mass, which corresponds with an increased risk for metabolic disorders, type 2 diabetes, and cardiovascular complications [1-4]. The relative loss of fat-free mass (FFM), an increase in fat mass, and abdominal fat distribution are further associated with physical impairments and a higher mortality rate [5-7]. Increased abdominal adipose tissue causes unfavorable changes in insulin sensitivity and plasma lipid values $[8,9]$. Subclinical inflammation of adipose tissue surrounding and infiltrating muscles is supposed to be one mechanism responsible for the muscular abnormalities in the aging process [10]. In obese patients, exaggerated loss of muscle mass can result in sarcopenic obesity [11], with a further increase in the cardiovascular risk [12].

One of the most important and effective developments in the pharmacological interventions to reduce cardiovascular complications was the introduction of statin therapy. Landmark studies and meta-analyses clearly demonstrated that statin therapy results in a significant reduction of cardiovascular morbidity and mortality $[13,14]$. This is also supported by recently published data from the Cholesterol Treatment Trialists' meta-analysis including data from $>170,000$ participants from 26 randomized statin trials [15]. In general, statins are well tolerated and safe, with myopathy as the most serious negative side effect [15-17]. Muscular damage during statin therapy ranges from muscle weakness, aches, and fatigue to rhabdomyolysis with the potential risk of renal failure. The occurrence of general myopathies has been estimated to range from 1 to $10 \%$, while rhabdomyolysis was reported to occur in $0.1 \%$ of all statin users $[14,17]$. The creatine phosphokinase (CPK) plasma levels serve as an indicator for muscle cell damage and death [14], but are also related to muscle mass [18, 19]. The risk of myopathy under statin therapy increases with an increasing dosage of the statin, in the case of multiple medication, and especially in elderly individuals [17].

Recently published retrospective analyses of statin studies indicate that statin therapy - despite the tremendous preventive effects on cardiovascular disease - might cause an increased risk of type 2 diabetes [20-22]. Evidence for a dose-dependent association between statin and diabetes risk was described in a meta-analysis [22], but the underlying mechanisms remain a matter of speculation. It could be hypothesized that distinct effects of statin therapy on muscle cells result in muscle insulin resistance [23]. Statin therapy could also affect the age-associated decrease in muscle strength and muscle mass [1, 24, 25]. Myopathy under statin therapy is multifactorial. A modulation of the respiratory chain of mitochondria $[26,27]$, an increase in muscle cell apoptosis [16], and an upregulation in the expression of genes that modulate membrane repair were described as a part of the complex underlying mechanism of statin myopathy [28].

Regarding the debate about a possibly increased incidence of type 2 diabetes under statin therapy and the side effects of statins on muscle cells, it seemed of interest to us to study whether statin therapy is related to an exaggerated aging-associated decrease in FFM. For this purpose, a cohort of patients with and without statin therapy was assigned to different age groups. To analyze the effect of statin use on the FFM, we regress a patient's FFM on the statin use and on other control variables.

\section{Patients and Methods}

Between January 2005 and July 2011, a total of 3,280 persons attended a medical outdoor center for diagnostic and/or therapeutic interventions. All patients underwent clinical routine controls and laboratory measurements. The level of physical exercise was determined by the reported frequency of sporting activities per week. 
Dzien et al.: Fat-Free Mass and Fasting Glucose Values in Patients with and without

Statin Therapy Assigned to Age Groups between $<60$ and $>75$ Years

Laboratory tests were performed from blood samples taken in the morning after an overnight fasting period. Patients were asked to restrain from vigorous physical exercise $48 \mathrm{~h}$ before the laboratory and clinical measurements were performed. Total CPK activity was determined by 'Menarini autoanalyzer reagent FGENT CK-NAC MONO', and normal CPK activity ranged from 24 to $170 \mathrm{U} / \mathrm{l}$.

Body composition (lean mass, fat mass, proportion of fat mass) of the patients was estimated using bioelectrical impedance analysis with body composition monitor HBF-306-E 'OMRON' bipolar devices [29, 30]. Information on BMI and on FFM was collected from all patients [29, 30].

Patients were assigned to 3 age groups from $<60$ to $>75$ years of age, thereby also separating patients with and without statin therapy. The patients were defined as statin users when a continuous intake of statins was reported for at least 4 weeks (duration of medication 1-78 months). A sub-analysis was performed for patients under statin therapy with CPK values in the normal range compared to those with CPK values above $170 \mathrm{U} / \mathrm{L}$. None of the patients revealed renal impairments. A further assignment of the patients into 3 groups was performed according to the body mass index (BMI) - with normal BMI $\left(<25 \mathrm{~kg} / \mathrm{m}^{2}\right)$, overweight $(25-30$ $\left.\mathrm{kg} / \mathrm{m}^{2}\right)$, and obesity $\left(>30 \mathrm{~kg} / \mathrm{m}^{2}\right)$.

Patients with acute vascular complications (myocardial infarction, coronary interventions, stroke, cerebral ischemia within 12 weeks), acute or chronic inflammatory disease, severe renal or hepatic failure or chemotherapy, or non-statin lipid-lowering drug therapy were excluded from our evaluation.

No changes in lifestyle during the last 3 months were stated by the patients, and none of the patients reported about a current weight reduction program. Beside the clinical status, an increased erythrocyte sedimentation rate, $\mathrm{C}$-reactive protein and leukocyte count were the diagnostic criteria for inflammatory disease. Renal disease was defined by a serum creatinine $>1.5 \mathrm{mg} / \mathrm{dl}$ and impaired liver function by a double or higher increase of hepatic enzyme levels.

The share of people engaging in regular sports activities was about $43 \%$, while approximately $24 \%$ patients in our sample were smokers and $11 \%$ were patients with diagnosed type 2 diabetes mellitus.

Informed consent about the participation in the study was requested from all of the patients.

Statistical Analysis

First of all, we applied a descriptive analysis by which we compared FFM of statin users and non-statin users across different age cohorts. Furthermore, in order to analyze the impact of statin use on FFM more systematically, we regressed a patient's FFM on an indicator variable informing about statin use, an interaction term between statin use and age, and other control variables. The latter include a patient's age (in years), gender (dummy variable, entry 1 indicating male patients), and two indicator variables informing about nicotine consumption (entry 0 for non-smokers and entry 1 for smokers) and sporting activities (entry 1 for patients engaging in sporting activities at least once a week, and entry 0 for all other patients). In all regressions, we used standard ordinary least-squares methods and excluded outlying observations at the upper and lower percentile of the remainder error ( $2 \%$ of the sample, or about 60 observations). We applied our regressions to two samples, one including all patients and one including only patients with CPK levels below $170 \mathrm{U} / \mathrm{l}$.

\section{Results}

In the whole study cohort of 3,280 patients a total of 600 patients were on continuous statin therapy, and 2,680 were non-users of statins. The highestfrequency of statin prescription was in the age group 60-75 years. 131 (21.8\%) of the patients on continuous statin therapy revealed increased $\mathrm{CPK}$ values. None of them developed an impaired renal function.

BMI revealed a decrease, with the lowest values in the oldest age group, i.e. $>75$ years, in patients with and without statin therapy (table 1). FFM decreased continuously with increasing age. The loss of FFM between the age group $<60$ years and $>75$ years was more pronounced in statin-treated patients (10.88\%) than in non-statin users (8.47\%). This was paralleled by a decrease in CKP-values, with a difference of $7.77 \mathrm{U} / 1$ between the age groups $<60$ and $>75$ years in non-statin users and of $14.75 \mathrm{U} / \mathrm{l}$ in statin users.

In statin users and in non-statin users the percentage of fat mass increased continuously with aging, with the highest values in the age group $>75$ years. In all age groups the BMI and 
Dzien et al.: Fat-Free Mass and Fasting Glucose Values in Patients with and without Statin Therapy Assigned to Age Groups between $<60$ and $>75$ Years

Table 1. Sample characteristics

\begin{tabular}{|c|c|c|c|c|c|c|c|c|}
\hline Age cohort & Observed & BMI & BFM & FFM & $\mathrm{CPK}$ & FGL & Total c & TG \\
\hline \multicolumn{9}{|c|}{ Non-statin users } \\
\hline$<60$ & 1,978 & 24.08 & 23.80 & 52.99 & 119.34 & 93.71 & 203.94 & 114.46 \\
\hline $60-75$ & 404 & 26.10 & 32.40 & 50.87 & 122.73 & 108.38 & 227.73 & 131.29 \\
\hline$>75$ & 298 & 24.58 & 34.54 & 44.52 & 111.57 & 113.00 & 219.82 & 130.34 \\
\hline Total & 2,680 & 24.44 & 26.29 & 51.73 & 118.99 & 98.10 & 209.34 & 118.80 \\
\hline \multicolumn{9}{|l|}{ Statin users } \\
\hline$<60$ & 152 & 27.46 & 29.28 & 58.37 & 133.18 & 113.20 & 226.46 & 176.99 \\
\hline $60-75$ & 293 & 26.68 & 32.53 & 51.85 & 135.78 & 113.93 & 210.17 & 151.18 \\
\hline$>75$ & 155 & 25.84 & 34.68 & 47.49 & 118.43 & 116.48 & 212.76 & 138.69 \\
\hline Total & 600 & 26.66 & 32.26 & 52.38 & 130.64 & 114.40 & 214.98 & 154.50 \\
\hline \multicolumn{9}{|c|}{ Statin users with $C P K>170$} \\
\hline$<60$ & 39 & 28.35 & 29.10 & 60.99 & 232.24 & 117.96 & 227.02 & 177.98 \\
\hline $60-75$ & 69 & 27.07 & 32.14 & 53.60 & 260.70 & 111.93 & 199.20 & 164.93 \\
\hline$>75$ & 23 & 26.16 & 33.38 & 50.36 & 268.70 & 128.20 & 207.43 & 145.04 \\
\hline Total & 131 & 27.29 & 31.45 & 55.23 & 253.63 & 116.59 & 208.93 & 165.32 \\
\hline BMI cohort & Observed & Age & BFM & FFM & $\mathrm{CPK}$ & FGL & Total c & $\mathrm{TG}$ \\
\hline \multicolumn{9}{|c|}{ Non-statin users } \\
\hline$<25$ & 1,656 & 43.70 & 22.83 & 48.02 & 109.81 & 93.94 & 205.35 & 103.96 \\
\hline $25-30$ & 706 & 52.86 & 29.69 & 56.19 & 136.61 & 102.21 & 216.53 & 138.88 \\
\hline$>30$ & 317 & 52.60 & 36.80 & 61.10 & 127.78 & 110.43 & 214.01 & 150.86 \\
\hline Total & 2,679 & 47.17 & 26.29 & 51.72 & 119.00 & 98.10 & 209.34 & 118.80 \\
\hline \multicolumn{9}{|l|}{ Statin users } \\
\hline$<25$ & 225 & 68.67 & 29.07 & 46.45 & 125.25 & 107.63 & 218.96 & 140.62 \\
\hline $25-30$ & 253 & 66.76 & 32.33 & 54.37 & 130.59 & 112.53 & 213.37 & 153.93 \\
\hline$>30$ & 122 & 65.53 & 37.99 & 59.18 & 140.70 & 130.60 & 211.06 & 181.06 \\
\hline Total & 600 & 67.23 & 32.26 & 52.38 & 130.64 & 114.40 & 214.98 & 154.50 \\
\hline \multicolumn{9}{|c|}{ Statin users with $C P K>170$} \\
\hline$<25$ & 44 & 67.84 & 28.41 & 48.82 & 260.22 & 107.34 & 217.79 & 171.87 \\
\hline $25-30$ & 55 & 65.02 & 31.02 & 55.97 & 254.90 & 114.50 & 207.03 & 156.15 \\
\hline$>30$ & 32 & 64.07 & 36.38 & 62.77 & 242.39 & 132.88 & 200.00 & 172.07 \\
\hline Total & 131 & 65.73 & 31.45 & 55.23 & 253.63 & 116.59 & 208.93 & 165.32 \\
\hline
\end{tabular}

$\mathrm{BFM}=$ body fat mass in \%; FFM = fat-free mass in \%; $\mathrm{CPK}=$ creatine phosphokinase $(\mathrm{U} / \mathrm{l}) ; \mathrm{FGL}=$ fasting glucose $(\mathrm{mg} / \mathrm{dl})$; total $\mathrm{c}=$ total cholesterol $(\mathrm{mg} / \mathrm{dl}) ; \mathrm{TG}=$ triglycerides $(\mathrm{mg} / \mathrm{dl})$.

corresponding FFM values were higher in statin users than in non-statin users (table 1), whereas a higher percentage of fat mass was only observed in the younger study group $<60$ years of age. Fasting glucose levels revealed a continuous increase with increasing age in nonstatin users and in statin users.

With respect to the data evaluation according to subgroups defined by the BMI values, non-statin users in the overweight and obese groups $\left(25-30 \mathrm{~kg} / \mathrm{m}^{2}\right.$ and $\left.>30 \mathrm{~kg} / \mathrm{m}^{2}\right)$ were older than in the normal-weight group $\left(<25 \mathrm{~kg} / \mathrm{m}^{2}\right.$ ) (table 1). Overall, statin users were older than non-statin users. The percentage of body fat mass in the BMI group $<25 \mathrm{~kg} / \mathrm{m}^{2}$ was higher in statin users than in non-statin users, while no such pronounced difference was found for overweight or obese patients. In all BMI groups statin users - except those with increased CPK values - showed lower values for FFM than non-statin users. Fasting glucose and triglyceride values revealed a continuous increase with increasing BMI in statin users and in non-statin users. In the BMI subgroups fasting glucose and triglyceride levels were higher in statin users compared to non-statin users (table 1). 
Dzien et al:: Fat-Free Mass and Fasting Glucose Values in Patients with and without Statin Therapy Assigned to Age Groups between $<60$ and $>75$ Years

Table 2. Impact of statin therapy on fat-free mass ${ }^{a}$

\begin{tabular}{lll}
\hline & All patients & Patients with CPK $\leq 170$ \\
\hline Sex $(1=$ male $)$ & $16.9298(0.2465)^{* * *}$ & $16.4383(0.2799)^{* * *}$ \\
Age & $-0.1274(0.0069)^{* * *}$ & $-0.1281(0.0075)^{* * *}$ \\
Nicotine consumption $(0=$ no; 1 = yes $)$ & $0.1427(0.2742)$ & $0.0274(0.2915)$ \\
Sports activity $(0=$ no; $1=$ yes $)$ & $0.1164(0.2285)$ & $0.3669(0.2495)$ \\
Statin use & $7.4048(1.8506)^{* * *}$ & $7.0191(2.0611)^{* * *}$ \\
Statin use $\times$ age & $-0.0947(0.0274)^{* * *}$ & $-0.0859(0.0305)^{* * *}$ \\
Observations & 3.214 & 2.613 \\
$R^{2}$ & 0.64 & 0.62 \\
\hline
\end{tabular}

${ }^{a}$ Constant suppressed. Standard errors in parentheses.

*** Indicates significance at the $1 \%$ level.

A more systematic picture of the relationship between FFM and statin use is provided in our regression results in table 2 . First of all, it can be seen that male patients obtained a higher FFM than female patients. Furthermore, age was associated with a lower FFM. Nicotine consumption and sporting activities played an insignificant role. Additionally, we found a (highly) significant parameter estimate for statin use, indicating that patients undergoing a corresponding therapy revealed a higher FFM. We also observed that this effect of statin therapy declined over age, which is indicated by the significantly negative coefficient on the interaction term between statin use and the age variable. This, in turn, suggests that the effect of statin therapy on FFM is more pronounced in younger patients than in older ones. Both findings, i.e. the positive coefficient on the statin variable and the negative one on the interaction term between statin use and age, are in accordance with the descriptive evidence from table 1. In conclusion, we cannot see any systematic differences regarding the effects of statin therapy on FFM (and also its change over years) between our sample of all patients and the one focusing on 2,613 patients, with CPK equal to or lower than $170 \mathrm{U} / \mathrm{l}$ (columns 1 and 2 in table 2).

\section{Discussion}

The results of our evaluation indicate that patients under statin therapy reveal a more pronounced aging-associated decrease in FFM between the age groups of $<60$ and $>75$ years than in patients without statin therapy. This loss of FFM could be due to the complex morbidity of statin-treated patients but also due to a possible direct influence on FFM. Multivariate analysis revealed a strong positive relationship of FFM to male sex and to statin use. The association of FFM with male sex is well known and explained by the anabolic hormone effects $[31,32]$.

BMI and FFM values were higher in all of the patients treated with statin than in those without statin therapy. This observation could partially be due to a higher level of physical exercise [33]. Recently published studies reported an increased lean mass following resistance training under statin therapy and a more favorable outcome during rehabilitation procedures in elderly patients [34, 35]. As body weight and BMI are indicators of FFM [36], the higher FFM in our statin patients might simply be explained by the higher BMI values.

CPK activity is known to be related to FFM $[18,19]$. Low CPK levels are related to muscle weakness [37], sarcopenia, and frailty [38]. In all of our patients, the lowest values for CPK, 
Dzien et al.: Fat-Free Mass and Fasting Glucose Values in Patients with and without Statin Therapy Assigned to Age Groups between $<60$ and $>75$ Years

BMI and FFM were found in the oldest age group, in statin-treated patients, and in those without statin therapy. This finding is in accordance with previously published epidemiological data and clinical studies concerning a decrease of BMI at an advanced age [39, 40], resulting in an increased risk for physical impairment and frailty [2].

Fat mass increases with increasing age $[5,6]$ and is related to a higher cardiometabolic risk, but also to a higher rate of muscle loss and sarcopenia [12]. Greater total and abdominal adipose tissue mass is associated with subclinical inflammation [41], a process possibly enhancing sarcopenia [42]. Because statins also show anti-inflammatory effects, it could be speculated that statins improve sarcopenia [43]. Recently, an improved outcome during inpatient rehabilitation was described during statin therapy in older people; however, no measurements on FFM were provided [35].

Fasting glucose values of all our patients revealed an increase with increasing age, and peak fasting glucose levels were found in patients $>75$ years with and without statin therapy. This aging-associated increase in fasting glucose levels was also described by several other studies $[44,45]$ and is primarily explained by the aging-associated increase in insulin resistance. In accordance with this, we could observe an increase in fat mass with increasing age, with a higher risk for insulin resistance $[8,9]$.

In patients without statin therapy, total cholesterol increased up to the age group of 60-74 years and decreased thereafter. This could be explained by aging-associated impairments of lipoprotein metabolism resulting in an increase in total cholesterol [46, 47]. Total cholesterol was the lowest in the age group $>75$ years, which was paralleled by a decrease of serum triglycerides in patients with statin therapy. This might be related to reduced food intake, with a high risk for malnutrition at an advanced age [2].

Limitations of our evaluation are the fact that all study participants were patients admitted to an outdoor center and not a cohort of healthy individuals. However, all of our study participants were community-dwelling subjects without significant functional impairments.

Our findings indicate that patients under statin therapy reveal a more pronounced decrease in FFM than patients without statin therapy. It remains speculative whether this relationship is causal as a consequence of statin myopathy or due to the higher morbidity in patients needing statin therapy. Considering statin long-term safety [48], further studies will be required especially for patients at an advanced age.

\section{Conclusions}

Patients under statin therapy revealed a more pronounced aging-associated decline in FFM than patients without statin therapy. Aging was related to an increase in fat mass in statin users and non-users, which was paralleled by an increase in fasting glucose values. Interventions to prevent a more pronounced decline in muscle mass could be of particular advantage for elderly patients under statin therapy.

\section{Disclosure Statement}

The authors declare no conflict of interest. No sponsorship was obtained for the study. 
Dzien et al.: Fat-Free Mass and Fasting Glucose Values in Patients with and without Statin Therapy Assigned to Age Groups between $<60$ and $>75$ Years

\section{References}

1 Koopman R, van Loon LJC: Aging, exercise, and muscle protein metabolism. J Appl Physiol 2009;106:20402048.

- 2 Fielding RA, Vellas B, Evans WJ, Bhasin S, Morley JE, Newman AB, Abellan van Kan G, Andrieu S, Bauer J, Breuille D, Cederholm T, Cahndler J, De Meynard C, Donin L, Harris T, Kannt A, Keime Guibert F, Onder G, Pappanicolaou D, Rolland Y, Rooks D, Sieber C, Souhami E, Verlaan D, Zamboni M: Sarcopenia: an undiagnosed condition in older adults. Current consensus definition: prevalence, etiology, and consequences. International working group on sarcopenia. J Am Med Dir Assoc 2011;12:249-256.

3 Wroblewski AP, Amati F, Smiley MA, Goodpaster B, Wright V: Chronic exercise preserves lean muscle mass in master athletes. Phys Sportmed 2011;39:172-178.

4 Lechleitner M: Obesity and the metabolic-syndrome in the elderly - a mini-review. Gerontology 2009;54: 253-259.

5 Wannamethee SG, Shaper AG, Lennon L, et al: Decreased muscle mass and increased central adiposity are independently related to mortality in older men. Am J Clin Nutr 2007;86:1334-134.

- 6 Han TS, Tajar A, Lean MEJ: Obesity and weight management in the elderly. Br Med Bull 2011;97:169-192

- 7 Zamboni M, Mazzali G, Zoico E, Harris TB, Meigs JB, Di Francesco V, Fantin F, Bissoli L, Bosello O: Health consequences of obesity in the elderly: a review of four unresolved questions. Int J Obes 2005;29:1011-1029.

- 8 Hunter GR, Chandler-Laney PC, Brock PW, Lara-Castro C, Fernandez JR, Gower BA: Fat distribution, aerobic fitness, blood lipids, and insulin sensitivity in African-American and European-American women. Obesity 2010;18:274-281.

- 9 DeNino WF, Tschernof A, Dionne IJ, Toth MJ, Ades PA, Sites CK, Poehlman ET: Contribution of abdominal adiposity to age-related differences in insulin sensitivity and plasma lipids in healthy nonobese women. Diabetes Care 2001;24:925-932.

$\checkmark 10$ Zoico E, Rossi A, Di Francesco V, Sepe A, Olioso D, Pizzini F, Fantin F, Bosello O, Cominacini L, Harris TB, Zamboni M: Adipose tissue infiltration in skeletal muscle of healthy elderly men: relationship with body composition, insulin resistance, and inflammation at the systemic and tissue level. J Gerontol A Biol Sci Med Sci 2010;65:295-299.

11 Waters DL, Baumgartner RN: Sarcopenic obesity. Clin Geriatr Med 2011;27:401-421.

12 Stephen WC, Janssen I: Sarcopenic-obesity and cardiovascular risk in the elderly. J Nutr Health Aging 2009; 13:460-468.

13 Mills EJ, Rachlis B, Wu P, Devereaux PJ, Arora P, Perri D: Primary prevention of cardiovascular mortality and events with statin treatments. A network meta-analysis involving more than 65,000 patients. J Am Coll Cardiol 2008;52:1769-1781.

$\checkmark 14$ The Task Force for the management of dyslipidemias of the European Society of Cardiology (ESC) and the European Atherosclerosis Society (EAS): ESC/EAS guidelines for the management of dyslipidaemias. Eur Heart J 2011;32:1769-1818.

15 Cholesterol Treatment Trialists' (CTT) Collaboration: Efficacy and safety of more intensive lowering of LDL cholesterol: a meta-analysis of data from 170,000 participants in 26 randomized control trials. Lancet 2011; 376:1670-1681.

16 Dirks AJ, Jones KM: Statin-induced apoptosis and skeletal myopathy. Am J Physiol Cell Physiol 2006; 291:C1208-C1212.

17 Meador BM, Huey KA: Statin-associated myopathy and its exacerbation with exercise. Muscle Nerve 2010;42: $469-472$.

-18 Swaminathan R, Ho CS, Donnan SP: Body composition and plasma creatine kinase activity. Am J Clin Biochem 1988;25:389-391.

19 Mairiaux P, Buchet JP, Bettonville MN: Serum creatine kinase: relationship to lean body mass in a 'real-life' situation. Clin Chem 1984;30:1428-1429.

20 Sattar N, Preiss D, Murray HM, Welsh P, Buckley BM, de Craen AJ, Seshasai SR, McMurreay JJ, Freeman DJ, Jukema JW, Macfarlane PW, Packard CJ, Stott DJ, Westendorp RG, Sheperd J, Davis BR, Pressel SL, Marchiolo R, Marfisi RM, Maggiono AP, Tavazzi L, Tognoni G, Kjekshus J, Pedersen TR, Cook TJ, Gotto AM, Clearfield MB, Downs JR, Nakamura H, Ohashi Y, Mizuno K, Ray KK, Ford I: Statins and risk of incident diabetes: a collaborative meta-analysis of randomised statin trials. Lancet 2010;375:735-742.

21 Waters DD, Ho JE, DeMicco DA, Breazna A, Arsenault BJ, Wun CC, Kastelein JJ, Colhoun H, Barter P: Predictors of new-onset diabetes in patients treated with atorvastatin: results from 3 large randomized clinical trials. J Am Coll Cardiol 2011:57:1535-1545.

22 Tomlinson SS, Mangione KK: Potential adverse effects of statins on muscle. Phys Ther 2005;85:459-465.

-23 Preiss D, Seshasai SR, Welsh P, Murphy SA, Ho JE, Waters DD, DeMicco DA, Barter P, Cannon CP, Sabatine MS, Braunwald E, Kastelein JJ, de Lemos JA, Blaznig MA, Pedersen TR, Tikkanen MJ, Sattar N, Ray KK: Risk of incident diabetes with intensive-dose compared with moderate-dose statin therapy: a meta-analysis. JAMA 2011;305:2556-2564.

24 Mallinson JE, Constantin-Teodosiu, Sidaway J, Westwood FR, Greenhaff PL: Blunted Akt/FOXO signalling and activation of genes controlling atrophy and fuel use in statin myopathy. J Physiol 2009;587:219-230.

25 Scott D, Blizzard L, Fell L, Jones G: Statin therapy, muscle function and falls risk in community-dwelling older adults. QJM 2009;102:625-633. 
Dzien et al.: Fat-Free Mass and Fasting Glucose Values in Patients with and without

26 Gambelli S, Dotti MT, Malandrini A, Mondelli M, Stromillo ML, Gaudiano C, Federico A: Mitochondrial alterations in muscle biopsies of patients on statin therapy. J Submiscrosc Cytol Pathol 2004;36:85-89.

27 Sirvent P, Mercier J, Lacampagne A: New insights into mechanisms of statin-associated myotoxocity. Curr Opin Pharmacol 2008;8:333-350.

28 Draeger A, Sanchez-Freire V, Monastyrskaya K, Hoppeler H, Mueller M, Breil F, Mohaupt MG, Babiychuk EB: Statin therapy and the expression of genes that regulate calcium homeostasis and membrane repair in skeletal muscle. Am J Pathol 2010;177:291-299.

29 Kyle UG, Bosaeus I, DeLorenzo AD, Deurenberg P, Elia M, Gomez JM, Heitman BL, Kent-Smith L, Melchoir JC, Pirlich M, Scharfetter H, Schols AM, Pichard C; Composition of the ESPEN Working group: Bioelectrical impedance analysis - part I: review of principles and methods. Clin Nutr 2004;23:1226-1243.

30 Bosy-Westphal A, Later W, Hitze B, Sato T, Kossel E, Glüer CC, Heller M, Müller MJ: Accuracy of bioelectrical impedance consumer devices for measurement of body composition in comparison to whole body magnetic resonance imaging in dual-X ray absorptiometry. Obes Facts 2008;1:319-324.

-31 Zamboni M, Zoico E, Scartezzini T, Mazzali G, Tosoni P, Zivelonghi A, Gallagher D, DePergola G, Di Francesco V, Bosello O: Body composition changes in stable-weight elderly subjects: the effect of sex. Aging Clin Exp Res 2003;15:321-327.

-32 Vermeulen A, Goemaere S, Kaufman JM: Testosterone, body composition and aging. J Endocrinol Invest 1999; 22:S110-S116.

-33 Manini TM, Everhart JE, Anton SD, Schoeller DA, Cummings SR, Mackey DC, Delmonico MJ, Bauer DC, Simonsick EM, Colbert LH, Visser M, Tylavsky F, Newman AB, Harris TB: Activity energy expenditure and change in body composition in late life. Am J Clin Nutr 2009;90:1336-1342.

-34 Riechman SE, Andrews RD, Maclean DA, Sheater S: Statins and dietary and serum cholesterol are associated with increased lean mass following resistance training. J Gerontol A Biol Sci Acad Sci 2007;62:1164-1171.

-35 Lynch JE, Henderson NR, Ramage L, McMurdo ME, Witham MD: Association between statin medication use and improved outcomes during inpatients rehabilitation in older people. Age Ageing 2012;41:260-263.

-36 Sonati JG, Modeneze DM, Vilarth R, Maciel ES, Boccacetto ER: Body weight as an indicator of fat-free mass in active elderly women. Maturitas 2011;68:378-381.

37 Stucke G, Brühlmann P, Stoll T, Stucke S, Willer P, Michael BA: Low serum creatine kinase activity is associated with muscle weakness in patients with rheumatoid arthritis. J Rheumatol 1996;23:603-608.

-38 O'Connell K, Gannon J, Doran P, Ohlendieck K: Proteomic profiling reveals a severely perturbed protein expression pattern in aged skeletal muscle. Int J Mol Med 2007;20:145-153.

39 Jackson AS, Janssen I, Sui X, Church TS, Blair SN: Longitudinal changes in body composition associated with healthy aging men aged 20-96 years. Br J Nutr 2011;3:1-7.

40 Dzien A, Winner H, Theurl E, Dzien-Bischinger C, Lechleitner M: Body mass index in a large cohort of patients assigned to age decades between $<20$ and $>80$ years: relationship with cardiovascular morbidity and medication. J Nutr Health Aging 2011;15:536-541.

-41 Brinkley TE, Hsu FC, Beavers KM, Church TS, Goodpaster BH, Stafford RS, Pahor M, Kritchevsky SB, Nicklas BJ: Total and abdominal adiposity are associated with inflammation in older adults using a factor analysis approach. J Gerontol A Biol Sci Med Sci 2012;67:1099-1106.

-42 Cesari M, Kritchevsky SB, Baumgartner RN, Atkinson HH, Penninx BW, Lenchik L, Palla SL, Ambrosius WT, Tracy RP, Pahor M: Sarcopenia, obesity, and inflammation - results from the Trial of Angiotensin Converting Enzyme Inhibition and Novel Cardiovascular Risk Factor study. Am J Clin Nutr 2005;82:428-434.

-43 Bu DX, Griffin G, Lichtman AH: Mechanisms for the anti-inflammatory effects of statins. Curr Opin Lipidol 2011;22:165-170.

-44 Chandler-Laney PC, Phadke RP, Granger WM, Fernandez JR, Nunoz JA, Man CD, Cobelli C, Ovalle F, Gower BA: Age-related changes in insulin sensitivity and beta-cell function among European-American and AfricanAmerican women. Obesity 2011;19:528-535.

45 Dominguez LJ, Barbagallo M: The cardiometabolic syndrome and sarcopenic obesity in older persons. J Cardiomet Syndr 2007;2:183-189.

46 Kolovou G, Bilianou H, Marvaki A, Mikhailidis DP: Aging men and lipids. Am J Mens Health 2011;5:152-165.

47 Spinar J, Ludka O, Senkyrikova M, Vitovec J, Spinarova L, Dusek L: Cholesterol levels according to age. Vnitr Lek 2009;55:724-729.

48 Kohli P, Cannon CP: Statins and safety: can we finally be reassured? Lancet 2011;378:1980-1981. 